\title{
Chimney technique for aortic valve-on-valve replacement
}

Yoshito Inoue, MD, PhD, Soshu Kotani, MD, and Satoru Suzuki, MD, Hiratsuka, Japan

From the Department of Cardiovascular Surgery, Hiratsuka City Hospital, Hiratsuka, Japan.

Disclosures: Authors have nothing to disclose with regard to commercial support.

Received for publication May 8, 2017; revisions received July 8, 2017; accepted for publication July 24, 2017; available ahead of print Sept 14, 2017.

Address for reprints: Yoshito Inoue, MD, PhD, Department of Cardiovascular Surgery, Hiratsuka City Hospital,

1-19-1 Minamihara, Hiratsuka, Kanagawa 254-0065, Japan (E-mail: yoshito_inoue@ sky.plala.or.jp).

J Thorac Cardiovasc Surg 2018;155:68-9

$0022-5223 / \$ 36.00$

Copyright (c) 2017 by The American Association for Thoracic Surgery

http://dx.doi.org/10.1016/j.jtcvs.2017.07.085

$\checkmark$ Video clip is available online.

For bioprosthetic aortic valve failure, one of the lessinvasive treatments is transcatheter aortic valve replacement. Patients with multiple valve disease or with interventricular shunts, however, eventually need to undergo a standard reoperation. Explantation of the old prosthesis involves risks of annular disruption or blockage of conduction. The valve-on-valve technique is an alternative option, ${ }^{1}$ but it has not been applied to patients with small bioprostheses. $^{2}$ We describe a modified valve-on-valve procedure for implanting a new valve of equal size with a chimney graft.

\section{CLINICAL SUMMARY}

An 82-year-old woman who had undergone aortic valve replacement with a $19-\mathrm{mm}$ bovine bioprosthetic valve (CEP model 2900; Edwards Lifesciences, Irvine, Calif) for bicuspid aortic stenosis and patch augmentation of small aortic annulus (Nicks procedure) presented with heart failure 15 years later because of severe aortic regurgitation caused by failure of the prosthetic valve. Residual left-toright ventricular shunt was the exclusion criterion for transcatheter aortic valve replacement.

Surgery was performed through a median sternotomy. Because of severe adhesion of the heavily calcified Dacron polyester fabric patch that had been used for augmentation of left ventricular outflow tract, explantation of the old valve would have been very hazardous. Moreover, the valve was too small to facilitate the valve-on-valve procedure in the usual manner. A novel chimney technique was therefore used.

The previous leaflets were removed. To implant a 16-mm mechanical valve (ATS AP360; Medtronic Inc,

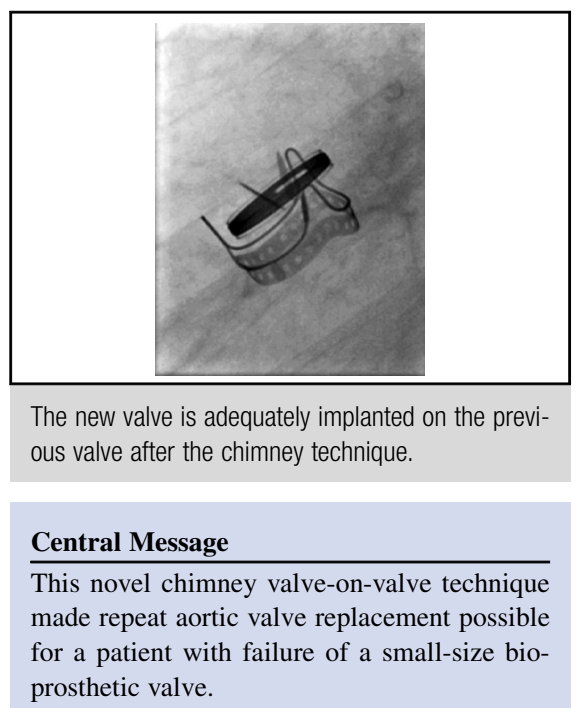

See Editorial Commentaries pages 70 and 72 .

Minneapolis, Minn) onto an 18-mm inner-diameter CEP valve, an 18-mm J-graft vascular prosthesis (Japan Lifeline, Tokyo, Japan) was sewn to the cuff (Figure 1). After that 20 Ethibond (Ethicon Inc, Somerville, NJ) mattress sutures were placed equally around the previous ring. All mattress sutures were passed through the chimney graft and were snared before tying to confirm that the valve was adequately seated horizontally and that the chimney graft was well seated on the previous ring and free from folding, deformity, or coronary obstruction (Figure 2). The sutures were tied as soon as free valve leaflet motion was confirmed (Video 1).

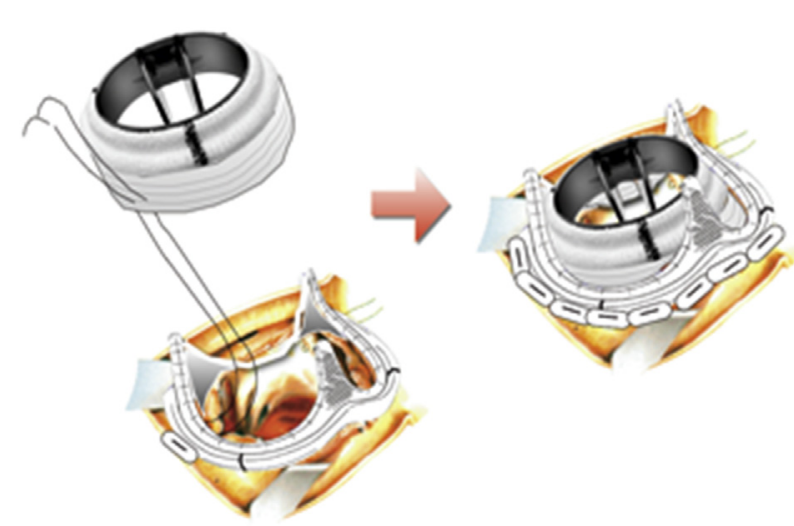

FIGURE 1. Schematic of the chimney technique. 


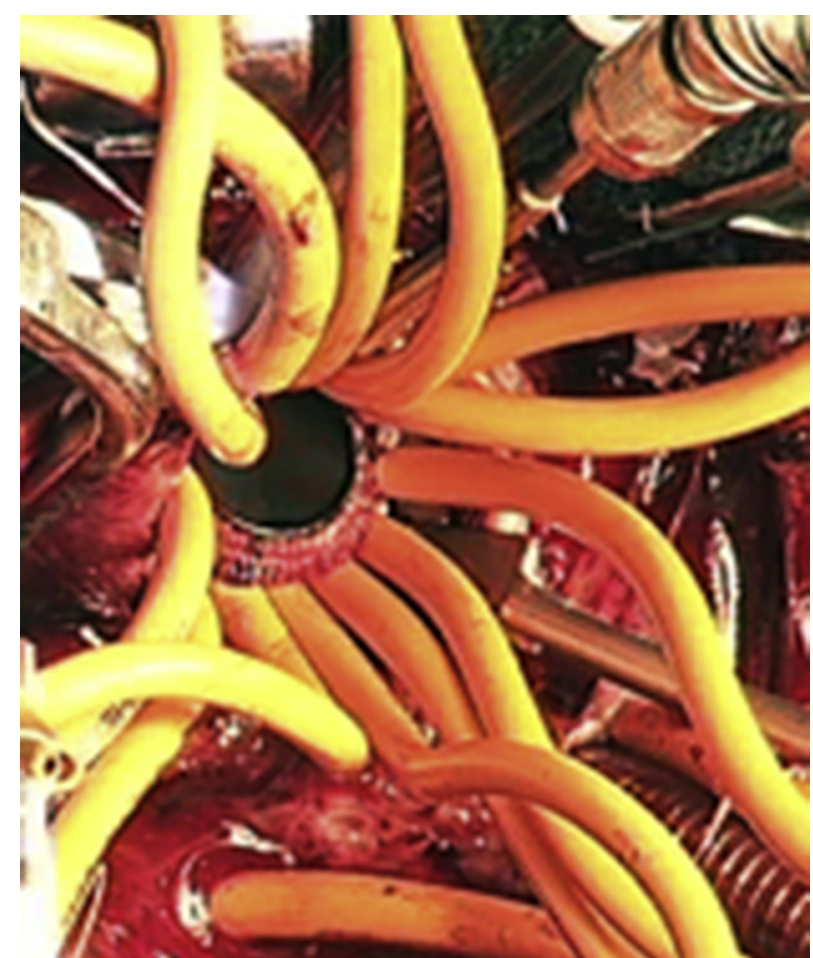

FIGURE 2. All mattress sutures were snared before tying to confirm adequate valve seating.

The new valve was adequately implanted. The woman has since been followed up uneventfully for 5 years in our outpatient clinic and is in New York Heart Association class I with normal sinus rhythm. An annual echocardiogram found normal valve function and good left ventricular function (ejection fraction, $77 \%$ ), with a low-grade pressure gradient (maximum pressure difference of $16 \mathrm{~mm} \mathrm{Hg}$ and mean difference of $6.4 \mathrm{~mm} \mathrm{Hg}$ ).

\section{DISCUSSION}

Our prerequisite for the choice of the valve-on-valve procedure has been the large size of the prosthetic valve inserted at the first operation. ${ }^{3}$ When implanting the new mechanical valve directly between the struts of the previous bioprosthesis, the size of the new prosthesis must be at least two sizes $(6-8 \mathrm{~mm})$ smaller in diameter than the previous valve. Unfortunately, no size-matched prosthesis exists for a $19-\mathrm{mm}$ valve that would facilitate the valve-on-valve procedure in the usual manner. The chimney graft interposition makes it possible to fit a new valve on the ring with the same

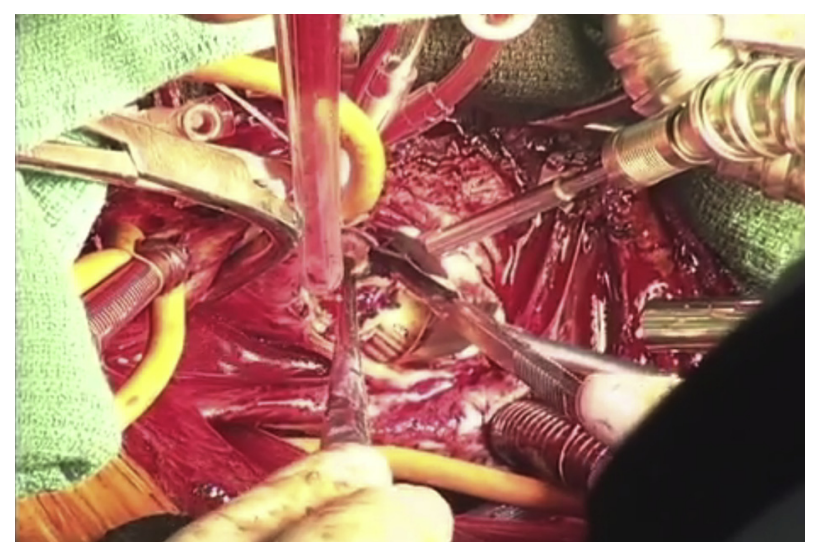

VIDEO 1. Only the previous valve leaflets were removed. A new valve with chimney graft was sewn onto the previous ring. All mattress sutures were passed through the graft and were snared before proper seating was checked. Video available at: http://www.jtcvsonline.org/article/S00225223(17)31800-7/fulltext.

size. It is helpful to secure extra space for the leaflet motion between rings of equal size. The graft also seats better to the sewing cuff of the previous ring, so that there is no possibility of paravalvular leakage.

Evaluation of the proper seating of the chimney valve is mandatory before tying. Reversible tourniquet snaring ${ }^{4}$ is effective in detecting whether the retained subvalvular structures disturbs leaflet motion, as well as ensuring that there is no deformity of the chimney graft.

\section{CONCLUSIONS}

The chimney valve-on-valve technique made repeat aortic valve replacement possible for a patient with failure of a small bioprosthetic valve. This is a simple and effective procedure, especially for high-risk elderly patients, even today in the transcatheter aortic valve replacement era.

\section{References}

1. Stassano P, Losi MA, Golino A, Gagliardi C, Iorio D, Marzullo M, et al. Bioprosthesis replacement with mechanical valve implantation on the bioprosthetic ring. Surgical and 2D echo considerations. Eur J Cardiothorac Surg. 1993;7: 507-10.

2. Stassano P, Musumeci A, Losi MA, Gagliardi C, Spampinato N. Mid-term results of the valve-on-valve technique for bioprosthetic failure. Eur J Cardiothoracic Surg. 2000; 18:453-7.

3. Geha AS, Massad MG, Snow NJ. Replacement of degenerated mitral and aortic bioprosthesis without explantation. Ann Thorac Surg. 2001;72:1509-14.

4. Baumgartner FJ, Omari BO, Stuart L, Milliken JC, Nelson RJ, Robertson JM. Reversible snaring for proper prosthetic seating during valve replacement. Ann Thorac Surg. 1998;66:957-8. 